\author{
Jean-Michel Jeannin
}

\section{Einleitung}

Punica granatum (Abb. 1, 2) ist ein kleiner, 5-6 Meter hoher Baum. Er stammt ursprünglich aus Westasien und Griechenland. Die scharlachroten Blüten sind 5- bis 7-zählig und weisen ein doppeltes Perianth auf. Die Früchte sind runde Beeren mit einer roten, derben Schale. Das Fruchtinnere ist durch dicke Trennwände in Kammern aufgeteilt, in denen bis zu 600 von einer roten saftigen Pulpa umschlossene Kerne angeordnet sind [1].

\section{Verwendung}

Der Granatapfel ist eine Speisefrucht und dient auch als Grundlage für den beliebten Sirup. Der Granatapfel wurde schon in Babylonien kultiviert, ebenso im Alten Ägypten, im antiken Griechenland und in Byzanz. In allen alten Kulturen war der Granatapfel ein Fruchtbarkeits- und Lebenssymbol.

\section{Traditionelle Verwendung}

Bis ins 20. Jahrhundert wurden $\mathrm{Zu}$ bereitungen aus den Blättern und der Rinde als Anthelminthikum verwen-

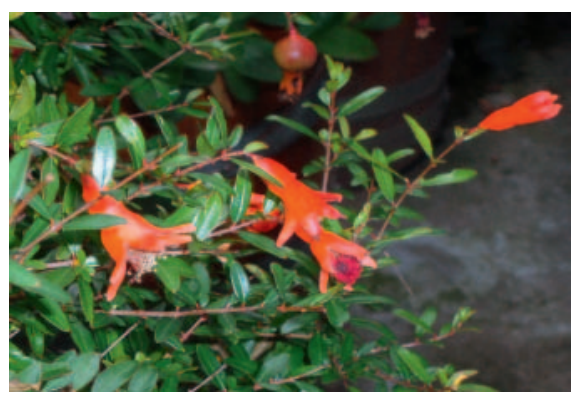

Abb. 1. Blüten, Zweige und Frucht von Punica granatum L. cv. Nana (Gartenform). Basel, Botanischer Garten, 2011.

\title{
Exotische Heilpflanzen (9)
}

\section{Punica granatum (L.) (Lythraceae)}

det. In der Tibetischen Medizin werden die Kerne zur Behandlung von Verdauungsstörungen verabreicht. In verschiedenen asiatischen Ländern gelten die Kerne als Stärkungsmittel und als Mittel gegen Anämie [1]. In Indien, Tunesien und Guatemala wird ein Dekokt der Fruchtschale als Adstringens verwendet [2]. In der ayurvedischen Medizin werden die Kerne zur Behandlung von Diabetes mellitus Typ 2 angewendet [3]. In der traditionellen arabischen Medizin werden dazu die Blüten genutzt [2].

\section{Phytochemie}

Der Granatapfel enthält Vitamin C $(20 \mathrm{mg}$ in $100 \mathrm{~g})$ sowie die Vitamine B1, B2, B6 und Folsäure [1]. Spezifische Tannine sind z.B. Granatin A und B, Punicacortein A, B, C, D in der Rinde oder Punicafolin in den Blättern. Flavone und Flavonole finden sich hauptsächlich in den Blättern und im Perikarp, z.B. Luteolin, Kaempferol, Quercetin, Apigenin, Naringin und Rutin. Anthocyanidin und Flavan-3-ole findet man im Perikarp und in den Blütenblättern [4]. Der Fruchtsaft enthält Melatonin,

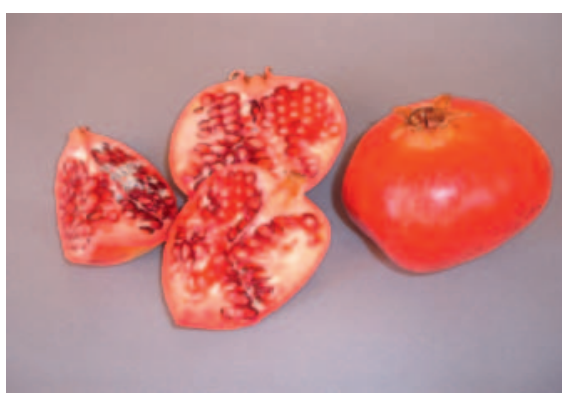

Abb. 2. Ganzer und aufgeschnittener Granatapfel. Die Früchte stammen aus dem Lebensmittelhandel.
Serotonin und Tryptamin. Pelletierin, N-Methylpelletierin und Pseudopelletierin findet man in der Rinde und in den Wurzeln, Pelletierin auch im Perikarp. Pelletierin vermittelt die anthelminthische Wirkung und gilt als toxisch [1]. In den Kernen wurden zahlreiche Steroide isoliert, darunter $17 \alpha$-Estradiol, Estrone, Estriol und Testosteron. Die Kerne enthalten 12 $20 \%$ Öle [2].

\section{Aktuelle Forschung}

Der Fruchtsaft zeigt ein präventives und therapeutisches Potenzial gegen Prostatakarzinom [5]. Ein gereinigter Polyphenolextrakt verhinderte in vitro die Replikation der RNA des Influenzavirus. Als wirksames Prinzip wurde Punicalagin identifiziert [6]. Erforscht wird auch das Potenzial zur Behandlung von Herz-KreislaufErkrankungen und von AIDS [2].

\section{Literatur}

1 La grenade Punica granatum L.; in Hostettmann $\mathrm{K}$ : Tout savoir sur les vertus thérapeutiques des fruits exotiques. Lausanne, Editions Favre, 2011.

2 Lansky EP, Newman RA: Punica granatum (pomegranate) and its potential for prevention and treatment of inflammation and cancer. J Ethnopharmacol 2007;109:177-206.

- 3 Saxena A, Vikram NK: Role of selected Indian plants in management of type 2 diabetes: a review. J Altern Complement Med 2004; 10:369-378.

4 Wang R, et al: Pomegranate: constituents, bioactivities and pharmacokinetics. FVCSB 2010;4(special issue 2):77-87.

$\checkmark 5$ Malik A, et al: Pomegranate fruit juice for chemoprevention and chemotherapy of prostate cancer. Proc Natl Acad Sci U S A 2005;102:14813-14818.

6 Haidari M: Pomegranate (Punica granatum) purified polyphenol extract inhibits influenza virus and has synergistic effect with oseltamivir. Phytomedicine 2009;16:1127-1136.

\section{KARGER}

Fax +49761 4520714 Information@Karger.de www.karger.com (c) 2011 S. Karger GmbH, Freiburg
Dipl. med. biol. Jean-Michel Jeannin Holeestrasse 43, 4054 Basel, Schweiz

Tel. +41 61-4215991, Fax -4230313

jmjeannin@dataworks.ch 